\title{
Design and simulation of point absorber wave energy converter
}

\author{
Devesh Singh ${ }^{1 *}$, Anoop Singh ${ }^{1}$, Akshoy Ranjan Paul ${ }^{1}$, and Abdus Samad ${ }^{2}$ \\ ${ }^{1}$ Motilal Nehru National Institute of Technology Allahabad, Prayagraj, India \\ ${ }^{2}$ Indian Institute of Technology madras, Chennai, India
}

\begin{abstract}
The paper aims to design and simulation of a wave energy harvesting system commonly known as point absorber for Ennore port located in the coastal area of Chennai, India. The geographical condition of India, which is surrounded by the three sides with seas and ocean, has enormous opportunity for power production through wave energy harvesting system. The wave energy converter device is a two-body floating system and its both parts are connected by power take-off unit which acts as spring mass damper system. In this paper, the hydrodynamic diffraction, stability analysis, frequency, and time response analysis is carried out on ansys-aqwa. The numerical results are compared with the results obtained from the similar experiments for validation of CFD solver. Effects of the properties featuring wave characteristics including wave height and wave period of Ennore port on the energy conversion, Froude-Krylov and diffraction force, response amplitude operator (RAO) are studied. Based on the study, float diameter, draft, geometry, and varying damping coefficient for power generation are optimized. Finally, the optimally designed point absorber is simulated as per Indian ocean energy harvesting standard and mass of the system, heave dimension, diffraction forces, and pressure variations are computed.
\end{abstract}

Keywords: floating point absorber, wave energy converter, damping coefficient

\section{Introduction}

In the present scenario of world energy consumption, more than $80 \%$ of the world's energy is obtained from fossil fuels. Since there is a limited source of fossil fuel reserve available on earth, continuous increase of global warming, and decline in the air quality, worldwide researchers are looking for new methods for the exploitation of renewable energy resources. Sea waves are an important source of environmental energy which can be changed into other forms of suitable energy as per demand for different purposes. In recent years, a lot of work has been done in this direction. Falnes [1] proposed a concept system to capture this wave energy. $\mathrm{He}$ also mentioned that a two-body point absorber arrangement utilizing a heave way to harvest energy from sea waves can harness the same energy as a 1-body heaving WEC system. $\mathrm{Yu}$ and $\mathrm{Li}$ [2] perform a numerical study on a two-body point absorber system by implementing Reynolds-average Navier-Stokes (RANS) based code without consideration of mooring effect.

Later Beirao and Malca [3] used finite element analysis in their study and utilize Simulink-based WECSim Matlab code to evaluate the performance of the heaving body floating point absorber system at an infinite depth, and from this numerical study, they concluded that spherical geometry shape is optimal.
Barbarit [4] used a frequency domain method to perform several numerical studies on power absorption of eight specifically selected wave energy converter systems at several installing locations. Beatty et al. [5] evaluate and compare the power extraction of two different types of submerged systems as similar to Wave Bob and OPT power buoy. They evaluate heave motion and hydrodynamic performance result of two 1:25 scale model of point absorber device. They also used a threepoint taut mooring system and evaluate the performance of the system.

Nazari et al. [6] study the performance of a two-body wave energy converting system for the Persian Gulf coastal area. They design different shapes and sizes of a buoy and evaluated their performance in respective wave conditions. There was a lot of work also done to improve the efficiency of the system. Goggins and Finnegan [7] use different criteria like the diameter of the buoy, damping coefficient, etc. to evaluate the net power extracted by the floating-point absorber system. Liang and Zuo [8] carried out numerical simulation and evaluate the frequency and time response analysis by using Ansys Aqwa commercial software for their study. They use this technology for power extraction which was used in oil and gas plants. Wu et al. [9] carried out detailed numerical simulation analysis and they found out that the net power extraction of a two-body heaving WEC system is heavily dependent on the physical

* Corresponding author : devesh@mnnit.ac.in 
system properties such as incident wave frequencies, buoy diameter, and shape, etc.

These detailed studies also motivate the bigger green energy firm to set large production goals in these new areas. One common and well-known example is OPTs Powerbuoy (figure 1).

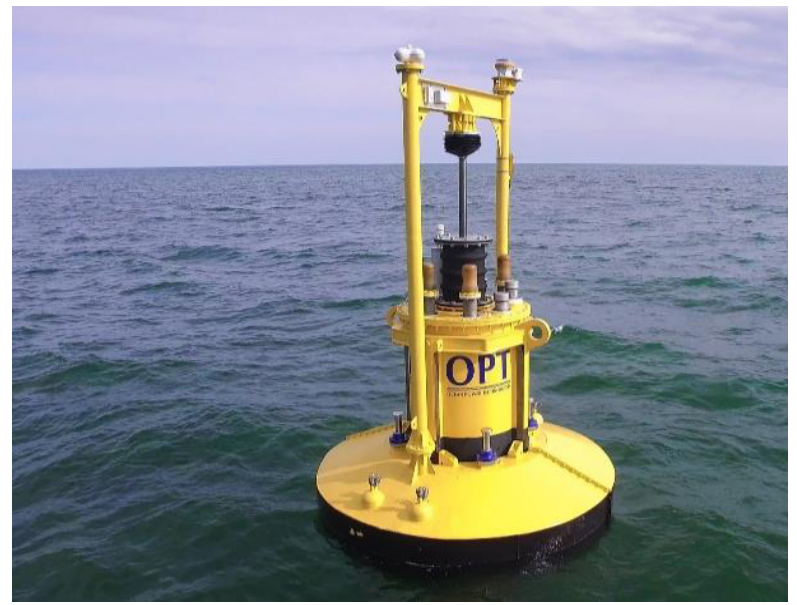

Fig. 1. Ocean power technologies Power buoy.

(Source: https://www.oceanpowertechnologies.com)

Since India is surrounded by ocean from three sides so there are numerous opportunities in the area of wave energy power extraction technologies. As per data, the power extraction in the Indian coastal area is $3 \mathrm{~kW}$ to $13 \mathrm{~kW}$ per unit length on the crest of the wave. The present study is focused on the design and simulation of a two-body point absorber system for Ennore port of Chennai, India.

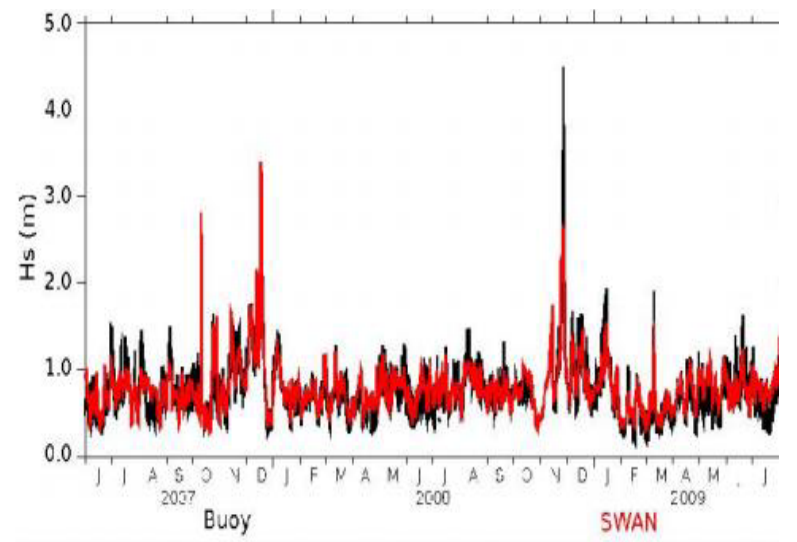

Fig. 2. Cumulative variation of wave height with time from 2007 to 2009; (Source: Nccr.gov.in)

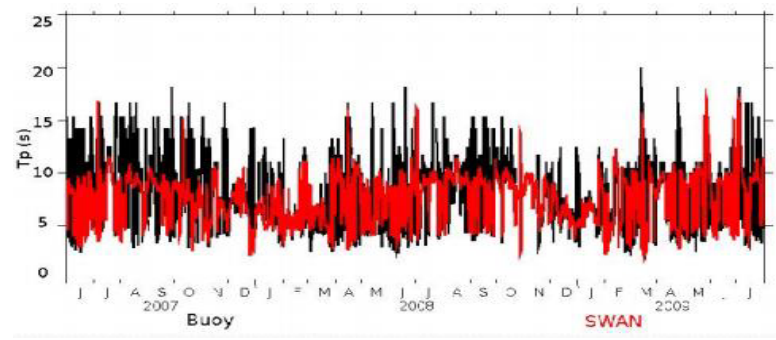

Fig. 3. Cumulative variation of wave period with time from 2007 to 2009; (Source: Nccr.gov.in)
Figures 2 and 3 show the comparison between the measured specific's height and period of the sea waves, respectively. Evaluating the wave data in a different season, the average variation of a time period of the Ennore port region is $4 \mathrm{~s}$ to $12 \mathrm{~s}$ and the average wave height variation is $0.4 \mathrm{~m}$ to $1 \mathrm{~m}$. The design and simulation of the point absorber which we stated here are inspired by OPT PowerBuoy.

\section{Analysis and modelling}

In the design stage, one can use SolidWorks for the initial drafting of the parts, since Ansys-Aqwa utilizes mass and moment of inertia as input in hydrodynamic diffraction analysis so SolidWorks helps to encounter such problem.

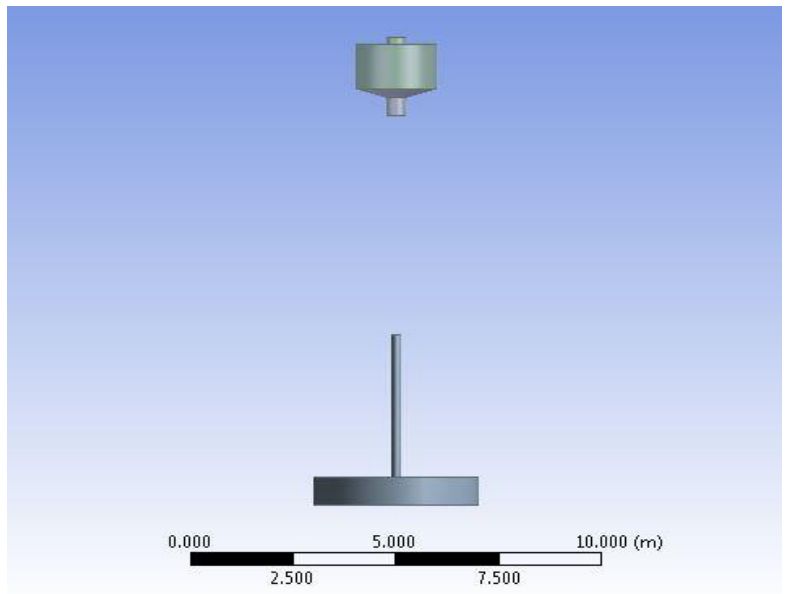

Fig. 4. The geometry of 2 body point absorber system

Then one goes for Ansys Aqwa design modular for further analysis. Figure 4 represents the cad model of two-body point absorber. In this analysis, the float diameter taken into the study is $2 \mathrm{~m}$ with spar length of $10 \mathrm{~m}$. The buoy weight taken here is $800 \mathrm{~kg}$ with $\mathrm{z}$ coordinate of COG at $0.55 \mathrm{~m}$ and the weight of the reaction heave system is $10087.24 \mathrm{~kg}$ with $\mathrm{z}$ coordinate of $\mathrm{COG}$ at $-11.32 \mathrm{~m}$ for the seawater plane. All dimensions and moments of inertia are taken here for the fixed reference frame.

\subsection{Mesh quality (Grid generation)}

In grid generation, basic control is taken into consideration. During meshing always keep defeaturing tolerance equal or less than half of the maximum element size. After grid independency analysis the Defeaturing tolerance is $0.07 \mathrm{~m}$ and the maximum element size is $0.14 \mathrm{~m}$ also the maximum allowed frequency is $1.474 \mathrm{~Hz}$. The number of diffraction nodes is 7600 , the number of diffraction elements is 7559 and the total number of elements is 10142 . 


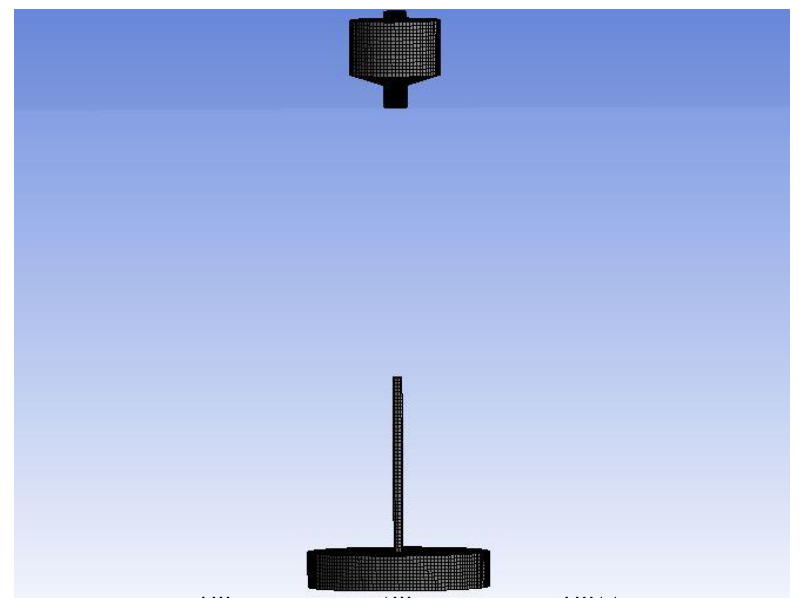

Fig. 5. The geometry of 2 body point absorber system

\subsection{Solver setting and boundary condition}

In the graph, size factor, global control, and geometric feature connections are taken as 5 and environment feature is also considered to 5 . The sea geometry took here for the depth of $100 \mathrm{~m}$ with water size, $X=500 \mathrm{~m}$, and water size, $Y=500 \mathrm{~m}$.

For buoy consider an added point mass with the weight of $800 \mathrm{~kg}$ and added direct input of inertia from Solidworks as $\mathrm{I}_{\mathrm{XX}}=334.45, \mathrm{I}_{\mathrm{YY}}=334.45$, and $\mathrm{I}_{\mathrm{ZZ}}$ was taken as 376.12. And for the reaction plate, the $\mathrm{z}$ point of the centre of gravity is taken for standard fixed reference of frame as $-11.32 \mathrm{~m}$. Here also we have taken direct input of inertia as $\mathrm{I}_{\mathrm{XX}}=114833.33, \mathrm{I}_{\mathrm{YY}}=$ 114833.33, and $I_{Z Z}$ took as 20126.65.

During the analysis setting, we have taken the wave grid size factor as 2. We have also taken "Yes" to ignore modeling rule violations in the common analysis option setting. In the common analysis option, we have taken into consideration the calculation of extreme low/ high frequencies, drift coefficient, multidirectional wave interaction, and full QTF matrix. In the output file option, we have considered ASCII hydrodynamic database.

In the structure selection option consider buoy and reaction plate, in wave direction setting we have taken input wave range from to, and the interval is taken off with a number of the intermediate direction of 7 . For Ennore port the wave period range is from 3 to $13 \mathrm{~s}$ and a number of intermediate values are taken to 98 to get a precise solution with good accuracy.

After getting the hydrodynamic diffraction analysis solution, connect the solution file as input to the stability analysis, frequency response analysis, and time response analysis. In time response analysis, we have introduced Pierson-Moskowitz wave type in introducing the wave spectrum. The significant wave height taken here is $1 \mathrm{~m}$.

\section{Result validation}

To validate the result of the simulation we compare our result from uc berkeley of point absorber with motion in heave direction. First validate the result of one body point absorber motion in heave direction, in their experiment they have taken buoy diameter of $11 \mathrm{~m}$ with
$3 \mathrm{~m}$ height and heave plate thickness of $0.84 \mathrm{~m}$ and diameter of $14 \mathrm{~m}$. In laboratory decay test the initial displacement found was $0.02 \mathrm{~m}$ and natural period obtained was $9 \mathrm{~s}$.

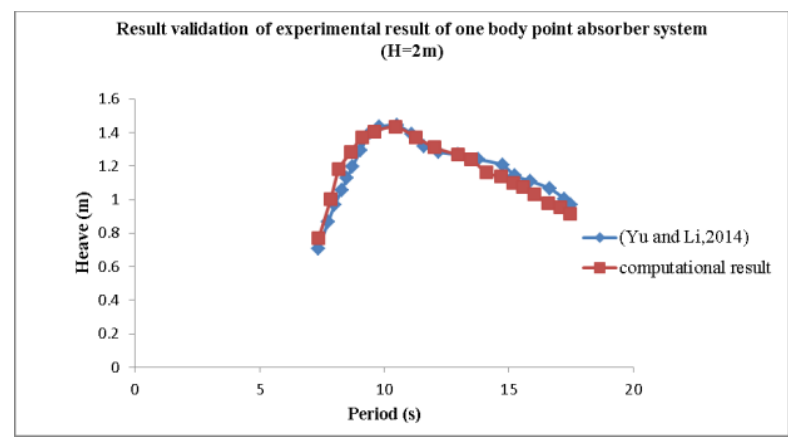

Fig. 6. Result validation of experimental result of one body point absorber system $(\mathrm{H}=2 \mathrm{~m})$

Figure 6 is the result validation for a single body point absorber system with an initial displacement of $0.02 \mathrm{~m}$ and an input wave height of $2 \mathrm{~m}$. The maximum percentage error in the solution is $5.79 \%$. After verification for single-body, one can go for a two-body heave system.

After validating the simulation result for single-body point absorber WEC system, verification of results for two-body heaving system has been carried out. Numerical simulation was carried out for $40.5 \mathrm{~m}$ structure of WEC with $11 \mathrm{~m}$ float diameter. Numerical simulation was carried out in frequency domain environment in Ansys Aqwa and the result was verified for Froude-krylov forces and added mass of the float system.

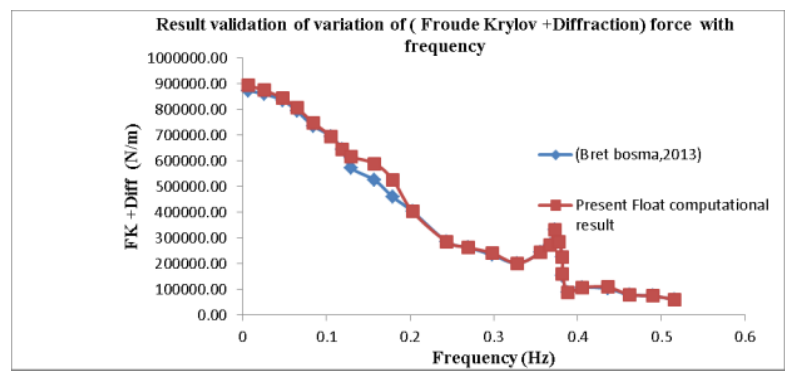

Fig. 7. Froude-Krylov force and frequency variation for 2body floating system

Figure 7 is the result validation for hydrodynamic Froude-krylov force variation with frequency. The maximum Froude-Krylov force acting on the WEC system is $900 \mathrm{kN} / \mathrm{m}$ with resonating frequency at $0.37 \mathrm{~Hz}$. The maximum percentage error in the validation is $12.25 \%$.

After validating the result for net excitation force on the structure, the next verification is the added mass variation with the frequency. 


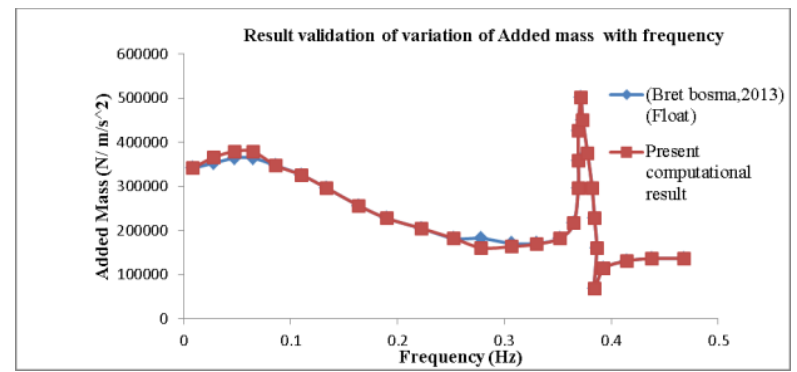

Fig. 8. Variation of added mass with frequency for 2 body heaving system

Figure 8 is the result validation for added mass variation with frequency. Here maximum added mass value is $500.47 \mathrm{~N} / \mathrm{m} / \mathrm{s}^{2}$ at frequency $0.37 \mathrm{~Hz}$ and the maximum percentage error in the validation is $13.3 \%$.

\section{Results and discussion}

After validating the simulation result with experimental wave tank test results, present research result is presented in this section. First result is variation of net excitation force (Froude-Krylov +Diffraction) with period.

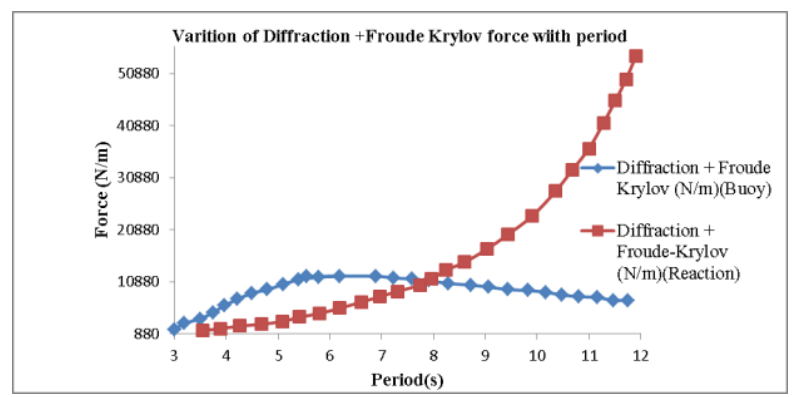

Fig. 9. Variation of Froude-Krylov + Diffraction force with wave period

Figure 9 shows the maximum net excitation force is $54.35 \mathrm{kN} / \mathrm{m}$ for the reaction plate and for the buoy system the maximum value is $11.95 \mathrm{kN} / \mathrm{m}$

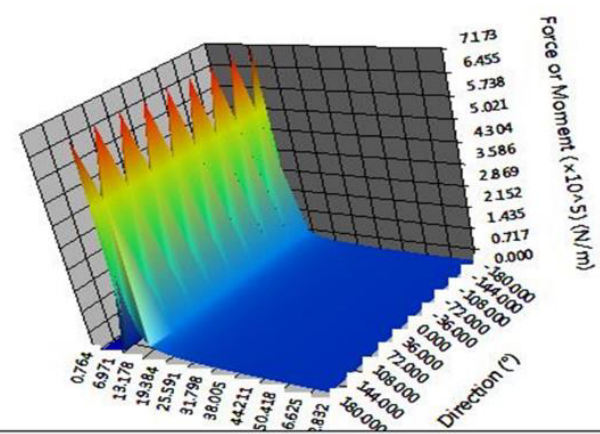

Fig. 10. Force/moment vs. Frequency \& direction) of (buoy)

After the variation of net excitation force with period, contour of force variation with frequency and direction has been proposed as shown in figure 10 . Frequency range is taken as per incoming wave frequency range of port and direction is taken from $-180^{\circ}$ to $180^{\circ}$ range.

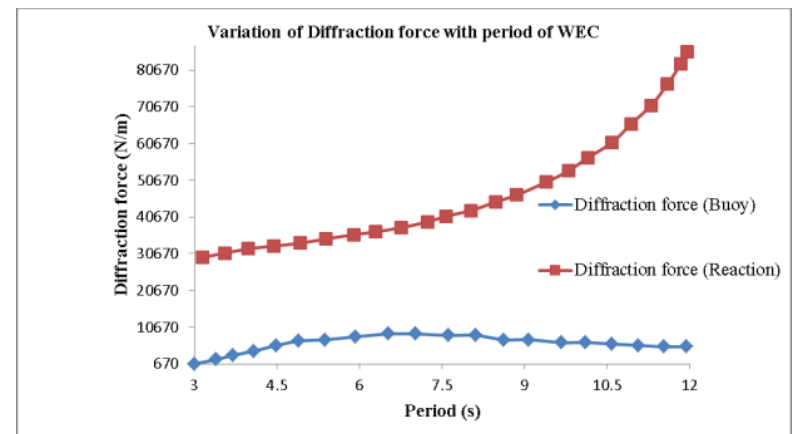

Fig. 11. Diffraction force variation with period of FPA

Figure 11 shows the variation of diffraction force with the period of the wec, where the maximum value of excitation forces for the reaction plate is $85.72 \mathrm{kN} / \mathrm{m}$ and for the buoy system it is $8.78 \mathrm{kN} / \mathrm{m}$. Here input period has been taken in seconds.

Next result is variation of the Response Amplitude Operator (RAO) with the period of incoming wave. RAO determine the effect of a state will have on a structure in the water and can be useful in determining the frequency at which maximum amount of power can theoretically be extracted. RAO has been measured in meter and period values are taken in seconds.

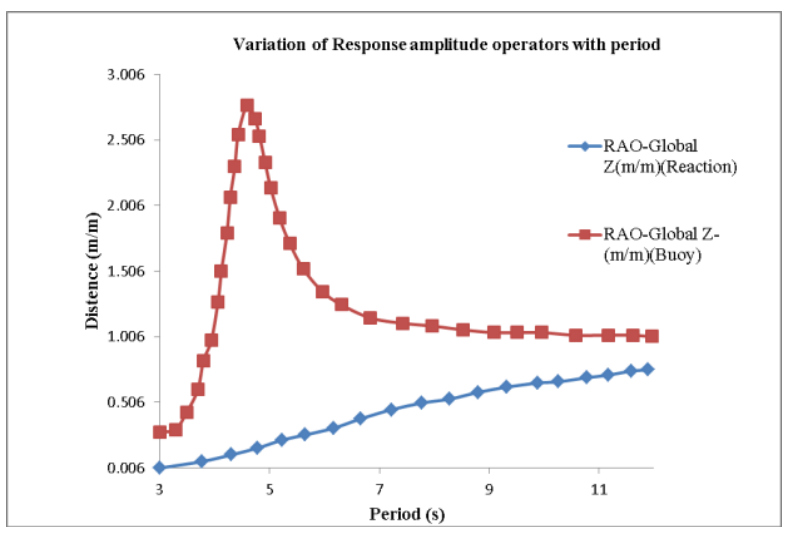

Fig. 12. Variation of response amplitude operator of buoy and heave parts for periods

Figure 12 shows the variation of response amplitude operator (RAO) with period for buoy and reaction system. Result obtained from the simulation shows that the maximum value of RAO for the buoy is $2.768 \mathrm{~m}$ at $4.59 \mathrm{~s}$ and the maximum value of RAO for the reaction system is $0.75 \mathrm{~m}$. So, the resonating frequency for the buoy system at which the WEC system shows maximum $\mathrm{RAO}$ response is $4.59 \mathrm{~s}$.

\section{Conclusions}

Present research work focus on the design and simulation analysis of the two body point absorber system for Ennore port area and carried out different aspect of analysis such as Froude-Krylov, diffraction force, response amplitude operator, added mass, hydrodynamics of buoy and reaction system, stability analysis and frequency domain analysis with the time response analysis. Due to modeling restriction in the 
ansys aqwa, power extraction is taken in linear fashion. Mooring effect on the system in this analysis is ignored.

Two-body point absorber is designed with the buoy diameter of $2 \mathrm{~m}$ and spar length of $10 \mathrm{~m}$ for the wave condition of Ennore port, India. Frequency domain method is employed to analyse the hydrodynamic performance of the two-body point absorber. Result obtained from the simulation shows that the resonating frequency for the buoy system at which the WEC system shows maximum RAO response is $4.59 \mathrm{~s}$, which can provide a reference for the maximum wave energy extraction.

\section{References}

1. J. Falnes, Marine Structures, 20, 185-201 (2007)

2. Y.H. Yu, Y. Li, Computers \& Fluids, 73, 104-114 (2013)

3. P. Beirao, C. Malça, International Journal of Energy and Environmental Engineering, 5(2), 1-11 (2014)

4. A. Barbarit, A. Clement, Applied Ocean Research, 28(2), 77-91 (2006)

5. S.J. Beatty, M. Hall, B.J. Buckham, P. Wild, B. Bocking, Ocean Engineering, 104, 370-386 (2015)

6. M. Nazari, H. Ghassemi, M. Ghiasi, M. Sayehbani, Iranica Journal of Energy \& Environment, 4(2), 130-135 (2013)

7. J. Goggins, W. Finnegan, Renewable Energy, 71, 208-220 (2014)

8. C. Liang, L. Zuo, Renewable Energy, 101, 265274 (2017)

9. B. Wu, X. Wang, X. Diao, W. Peng, Y. Zhang, Ocean Engineering, 76, 10-20 (2014)

10. B. Bosma, Oregon state university (2013) 